\title{
EDITORIAL
}

\section{What Factors Affect Health Seeking Behavior?}

\section{Abraham Haileamlak, MD, Professor of Pediatrics and Child Health}

Health seeking behavior has been defined as any action undertaken by individuals who perceive themselves to have a health problem or to be ill for the purpose of finding an appropriate remedy (1).

Attaining good health seeking behavior is an important element of prevention, early diagnosis and management of disease conditions. It helps in reducing cost, disability and death from diseases (2). However, good health seeking behavior cannot be achieved easily as it is guided by a decision-making process that is further governed by individuals and/or household behavior, community norms, and expectations as well as provider-related characteristics and behavior (3).

To understand the complex nature of health seeking behavior, it is imperative to note the two health behavior theories:

1. The Health Belief Model where the concept is the 'perceived susceptibility', which refers to the perceived chance of acquiring a condition. The 'perceived susceptibility' and the 'perceived severity' leads to the formation of 'perceived threat' of a certain condition. The likelihood of performing a certain health behavior is directly linked to the perceived threat, the perceived benefits, barriers of the suggested behavior change and the self-efficacy and the cues to action $(4,5)$.

2. The Theory of Planned Behavior relates the attitude towards behavior, subjective norms and perceived behavioral control to behavioral intentions and actions (6).

In general, it is essential to note that healthseeking behavior is complex, has no solo method to justify or create any pattern. Health seeking behavior is a reflection of the prevailing conditions, which positively interact to produce a form of care seeking but which remain fluid and therefore amenable to change. Immediate healthseeking is critical for appropriate management, and for this reason, understanding the determinants of health seeking behavior becomes critical in the bid to provide client oriented services.

The current issue, the second regular issue for the year 2018, contains an editorial, fourteen original articles and a case report focusing on various topics. One of the article in this issue deals with health seeking behavior among cervical cancer patients.

I invite readers to read through these articles and appreciate or utilize the contents. I also encourage readers to forward comments and suggestions to the editor or the corresponding authors.

\section{REFERENCES}

1. Ward H, Mertens $\mathrm{T}$ and Thomas C. Health seeking behaviour and the control of sexually transmitted disease. Health Policy and planning. 1997; 12:19-28.

2. World Health Organization. Dengue: Guidelines for Diagnosis, Treatment, Prevention and Control. WHO/HTM/NTD/DEN/2009.1. WHO, 2009.

3. Ihaji E, Gerald EU, Ogwuche CH. Educational level, sex and church affiliation on health seeking behaviour among parishioners in Makurdi metropolis of Benue state. JEPER. 2014;1:311-6.

4. Champion VL, Skinner CS. The health belief model. In: Health behavior and health education: Theory, research, and practice. San Francisco: John Wiley \& Sons, Inc.; 2008. p. 45-65.

5. Janz NK, Becker MH. The health belief model: A decade later. Health Education and Behavior. 1984;11(1):1-47.

6. Montaño DE, Kasprzyk D. Theory of reasoned action, theory of planned behavior, and the integrated behavioral model. In: Health behavior and health education: Theory, research, and practice. San Francisco: John Wiley \& Sons, Inc.; 2008. p. 67-92.

DOI: http://dx.doi.org/10.4314/ejhs.v28i2.1 